\title{
Experimental Study of the Dynamic Mechanical Behavior of Blast-Induced Cracks in Tensile Stress Field
}

\author{
Liyun Yang ${ }^{1, *}$, Chen Huang ${ }^{1}$, Chenxi Ding ${ }^{1}$, Huanzhen $X^{1}{ }^{1}$ and Yuh J. Chao ${ }^{2}$

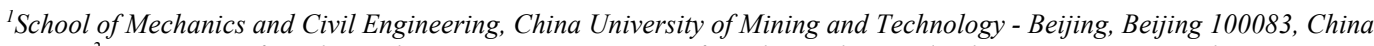 \\ ${ }^{2}$ Department of Mechanical Engineering, University of South Carolina, Columbia, SC 29205, United States
}

Received 23 August 2019; Accepted 12 December 2019

\begin{abstract}
The propagation behavior of blasting-induced cracks directly determines rock fragmentation and blasting effect. None of existing engineering blasting parameter design has considered the influence of initial tensile stress field on the propagation behavior of blast-induced cracks with a lack of theoretical and experimental guidance; therefore, the rock blasting effect in tensile stress field is far from ideal. The stress distribution and crack stress state around borehole under the coupling action of static tensile stress and blasting stress were determined based on the theory of elastic mechanics to reveal the propagation behavior of blast-induced cracks in the initial tensile stress field and the blasting fracture mechanism. Caustic method and digital laser dynamic caustic experimental system were combined to investigate and analyze laws influencing initial tensile stress and pre-crack angle on dynamic mechanical behavior, such as propagation velocity and dynamic stress intensity factor of blast-induced cracks in the tensile stress field. Results show that under the initial tensile stress field, the stress state of borehole wall in the direction of the vertical stress field is mainly circumferential tensile stress. Blast-induced cracks can easily experience crack initiation in this direction to form better crushing effect. The tensile stress field exhibits an inhibitory effect on the propagation of blast-induced cracks parallel to the direction of tensile stress while having a facilitating effect on the propagation of blast-induced cracks perpendicular to the direction of tensile stress. As the tensile stress field is enlarged, the propagation velocity, dynamic stress intensity factor, and propagation length of blast-induced cracks perpendicular to the direction of tensile stress can also increase. Furthermore, the enlarging pre-crack angle in the tensile stress field can postpone the attenuation of dynamic stress intensity factor and propagation velocity of blast-induced cracks and enlarge their attenuation amplitudes. This study can provide a theoretical guidance for engineering blasting practice in tensile stress field.
\end{abstract}

Keywords: Tensile stress field, Blast-induced cracks, Propagation velocity, Dynamic stress intensity factor, Caustics

\section{Introduction}

Blasting has been applied to all kinds of projects, such as tunnel and slope excavation, exploitation of mineral resources, and demolition of buildings (structures) [1, 2]. As the application fields of blasting are expanded, the initial static stress field (compressive or tensile stress field) generally appears in rock mass or building (structure). In the tunneling excavation process in deep rock mass, the rock mass in the excavation direction bears the action of ground stress field, which is under the action of initial compressive stress; therefore, the action of initial compressive stress field should be considered in blasting-assisted excavation. In the coal mining process, the roof strata are under the action of tensile stress field as the length of goaf increases, and the action of initial tensile stress field should be considered in the blasting-forced roof caving process. On the one hand, when blasting construction is conducted in initial static stress field, the initial static stress field changes the stress concentration state of media around boreholes; on the other hand, the initial static stress field influences the stress state of blast-induced cracks to change the propagation behavior of blast-induced cracks and blasting effect. Therefore, studying and expounding the blasting crushing mechanism

*E-mail address: yangly@cumtb.edu.cn

ISSN: 1791-2377 @ 2020 School of Science, IHU. All rights reserved.

doi:10.25103/jestr.131.24 under the action of initial static stress field (particularly tensile stress field) are necessary.

Traditional rock blasting theory, which does not consider the action of initial static stress field, has pointed out that after the blasting of explosives, the area from the borehole can be divided into crushing zone, crack zone, and elastic vibration zone from the near to the distant $[3,4]$. The crushing zone is mainly formed under a strong effect of blasting shock waves; the crack zone is formed when blasting gas drives microcracks in the crushing zone to further develop, and the media in the elastic vibration zone cannot experience evident damage. In general, the radius of the crushing zone is 2-3 times of that of borehole, whereas the radius of the crack zone is $8-12$ times of that of borehole. However, increasing scientific studies and engineering practices indicate that the blast zones and scopes in the initial static stress field differ from those specified in traditional blasting theory. Therefore, related contents of the traditional blasting theory cannot reasonably explain the blasting crushing behavior in the initial static stress field.

With the improvement of parallel computing power, numerical calculation methods (finite element, discrete element, etc.) have provided effective analytical means for numerous scholars to probe deeply into the dynamic blasting behavior in initial static stress field. However, these numerical calculation methods have gone through simplification and equivalence processing. As an example, a 


\section{Journal of Engineering Science and Technology Review 13 (1) (2020) 193 - 203}

loading wave curve with steep rising edge is used to characterize the action of blasting stress wave, and a loading wave curve with small peak value and long duration is used to characterize the action of blasting gas $[5,6]$. These calculation methods can simulate the action effect of blastinduced rock breaking to a certain degree, but such methods are quite at odds with the actual blasting action process. In addition, when the action of initial static compressive stress or tensile stress is considered, dynamic slackening method is generally used for processing [7,8], but describing initial stress state in rock mass is difficult. The reliability of research results is degraded due to these problems in combination with long-term lack of theoretical and experimental guidance in related studies.

Consequently, theoretical analysis and model experiment are combined in the present study to explore into dynamic behavior of blast-induced cracks in the static tensile stress field such as crack initiation and propagation. Furthermore, the combination of theoretical analysis and model experiment is expected to lay a research basis for blasting theory and engineering practice under complicated load conditions.

\section{State of the Art}

As a new research direction of the rock blasting theory and practice, considerable research regarding dynamic mechanical behavior of blast-induced cracks in initial static stress field (particularly tensile stress field) is still at the initial stage. To date, research related to dynamic blasting behavior of complete rock mass under the action of initial static compressive stress field has achieved preliminary research results. In a previous study, Wang et al. [9] combined finite element (LS-DYNA) and discrete element (UDEC) to simulate the destructive effect of initial ground stress on rock mass and found that rock mass experienced fracture at first along the direction of the maximum principal stress. Yang et al. [10, 11] found that when static compressive stress was parallel to the propagation direction of blast-induced cracks, the propagation of blast-induced cracks was facilitated. When static compressive stress was perpendicular to the propagation direction, the propagation was then repressed. Considering the influence of initial stress field in deep rock mass on rock failure mechanism, Yilmaz et al. [12] used the numerical simulation method to investigate the influencing laws of anisotropic initial static stress field on blasting effect and destruction area. In engineering practices, Kwon et al. [13] pointed out in the blasting construction of deep-buried tunnel the importance of understanding and evaluating the influence of deep initial stress field on blasting excavation behavior. In the blasting excavation process of underground hydropower station, Lu et al. $[14,15]$ found that initial static stress field in deep rock mass had a remarkable influence on crack propagation in borehole-blasting construction and pointed out that the blasting design for deep rock mass in accordance with the blasting parameters of shallow rock mass was unreasonable. The aforementioned research phenomenologically analyzes the propagation behavior of blast-induced cracks in initial static stress field with a lack of theoretical analysis and quantitative research. The popularization and application of research conclusions are quite restricted.

Defects such as joints and empty holes generally exist in rock mass or building (structure), which can have remarkable effects on dynamic mechanical behavior of blasting or impact fracture. Therefore, scientific researchers have carried out research from various aspects and obtained certain research results, which can be of guiding importance. As an example, based on mixed displacement technology, Soh [16] used finite element method to conduct a detailed analysis of the influence of material defects on dynamic behavior of cracks. Haeri et al. [17] further verified the great influence of original cracks in rocks on the propagation and run-through of newly developed cracks through laboratory experiment. Bhandari et al. [18] conducted a model experimental study on the destruction of joint-containing rock under blasting load and discussed the single-joint surfaces with different tilt angles and the relationship between boreholes and joint surfaces. Babanouri et al. [19] pointed out that cracks in rock mass had evident influence on the propagation of blasting stress wave, proposed a new method used to analyze the propagation characteristics of blasting stress waves in crack-containing rock mass, and established the relation to basic mechanical properties of rocks. Li et al. [20] combined model experiment and numerical calculation method to investigate the influence of empty holes on propagation path and dynamic mechanical behavior of blast-induced cracks and pointed out that blasting parameters could be optimized by taking advantage of the action characteristic of empty holes in engineering practices.

Based on the abovementioned research, the influence of defects on dynamic behavior and blast-induced cracking characteristics of rock mass is quite complicated. Therefore, the dynamic response of defect-containing media to blasting under the action of initial static stress field can be more complicated. Related scientific researchers have carried out preliminary research. Aliabadian et al. [21] used discrete element to investigate reflection and transmission behavior of blasting stress waves at joints in initial static compressive stress field and pointed out that initial stress field and joint restricted further propagation of blast-induced cracks in distant region. Yang et al. [22] used caustic experimental method to study the propagation laws of blast-induced cracks in pre-crack-containing media under the action of static compressive stress and analyzed the relationship between crack initiation angle and pre-crack angle. In addition, Yang et al. [23] explored into the response of jointed rock mass to blasting under the action of static compressive stress field via model experiment, analyzed crack initiation mode and angle at joints and stress intensity factor and cracking velocity, and pointed out that static compressive stress field elevated the shear failure degree triggered by crack initiation at joints.

The abovementioned research has primarily focused on the dynamic response problem of complete rock mass or defect-containing rock mass to blasting in the initial static compressive stress field. On the one hand, the aforementioned research lacks theoretical analysis; on the other hand, the propagation behavior of blast-induced cracks in initial static tensile stress field has been less investigated. Static tensile stress field exists in all kinds of blasted media. In practical engineering, when the tensile medium is in the middle of blasting construction, the influence of tensile stress on blast-induced cracks is remarkable. When tensile structures in large-scale soil engineering building are demolished directionally, tensile stress can influence the blasting demolition quality. In coal mining process, upper roof will not collapse within a long time due to the robustness of coal seam roof; however, a large-area tensile hanging arch is formed. When the tensile hanging arch is 
Liyun Yang, Chen Huang, Chenxi Ding, Huanzhen Xie and Yuh J. Chao/

Journal of Engineering Science and Technology Review 13 (1) (2020) 193 - 203

demolished via blasting, partial hanging arch is under superposed action of blasting stress and tensile stress. Under specific circumstances, excavation and unloading give rise to stress redistribution to generate tensile stress in rock mass or soil engineering building. In addition, the directional blasting effect can also be reached by applying tensile stress of boreholes. Therefore, exploring into the propagation laws of cracks in tensile stress zone can be of importance.

Therefore, for the deficiencies in the existing research, the dynamic response problem of complete rock mass and defect-containing rock mass to blasting in tensile stress field is systematically analyzed, followed by a detailed study of dynamic behavior of blast-induced cracks. The rest of the current study is arranged as follows: Section 3 expounds the experimental design and experimental system; Section 4 investigates the stress distribution of circular holes and deflection of blast-induced cracks under the action of dynamic and static stress fields through theoretical analysis and analyzes experimental results of three-group specimens such as failure characteristics, crack length, crack velocity, and dynamic stress intensity factor. Conclusions are summarized in Section 5.

\section{Methodology}

\subsection{Experimental design}

Kutter [24] and Rossmanith [25] verified that polymethyl methacrylate (PMMA) had similar dynamic fracture characteristics to brittle rock through experiment and only differed in breaking scope and crack propagation length. In addition, PMMA was applicable to experimental research on caustics due to good stress optical parameters. Therefore, PMMA was selected as the model experimental material. The dimensions of PMMA specimen were $320 \mathrm{~mm} \times 300$ $\mathrm{mm} \times 5 \mathrm{~mm}$, and the dynamic mechanical parameters were measured as shown in Table. 1.

Table. 1. Dynamic mechanical parameters of PMMA

\begin{tabular}{ccccc}
\hline $\begin{array}{c}\text { Optical constant } \\
\left(\mathrm{m}^{2} / \mathrm{N}\right)\end{array}$ & $\begin{array}{c}\text { Density } \\
\left(\mathrm{kg} / \mathrm{m}^{3}\right)\end{array}$ & $\begin{array}{c}\text { Velocity of the } \mathbf{S}- \\
\text { wave }(\mathbf{m} / \mathbf{s})\end{array}$ & $\begin{array}{c}\text { Velocity of the P- } \\
\text { wave }(\mathbf{m} / \mathbf{s})\end{array}$ & $\begin{array}{c}\text { Elasticity modulus } \\
\left(\mathrm{GN} / \mathrm{m}^{2}\right)\end{array}$ \\
\hline $1.08 \times 10^{-10}$ & 1230 & 1260 & 2320 & 6.1 \\
\hline
\end{tabular}

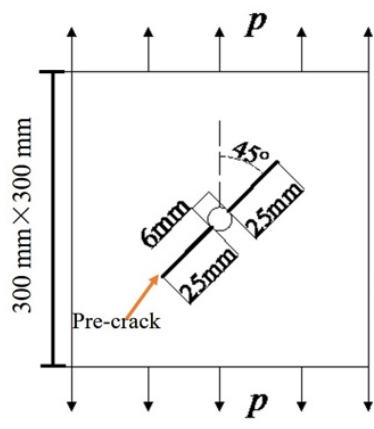

(a)

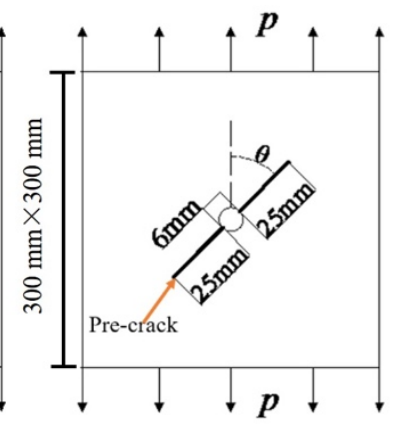

(b)

Fig. 1. Schematic diagrams of specimens M2 and M3

Three experimental model groups were identified in the present study: M1, M2, and M3. In the M1 group, the propagation laws of blast-induced cracks in circular boreholes under the action of blasting stress and tensile stress were explored. Circular holes with diameter of $d=6$ $\mathrm{mm}$ were set in the middle of each specimen model. On the basis of different initial stress values $p$, the specimens were named M1-0 ( $p=0 \mathrm{MPa}), \mathrm{M} 1-1(p=2.5 \mathrm{MPa}), \mathrm{M} 1-2(p=$ $5 \mathrm{MPa})$, and M1-3 $(p=10 \mathrm{MPa})$. In addition, the M2 group was used to investigate the propagation behavior of blastinduced cracks in specimens with pre-cracks of tilt angle of $45^{\circ}$ under different static compressive stresses (specimen model is shown in Fig. 1 (a)). Pre-cracks with length of 50 $\mathrm{mm}$ and tilt angle of $45^{\circ}$ existed at the center of each specimen, and circular holes with diameter of $6 \mathrm{~mm}$ existed at the center of pre-cracks. Given the difference of dynamic and static loads, specimens were numbered M2-0 ( $\sigma_{\mathrm{d}}=0$ $\mathrm{MPa}, p \neq 0 \mathrm{MPa}), \mathrm{M} 2-1\left(\sigma_{\mathrm{d}} \neq 0 \mathrm{MPa}, p=0 \mathrm{MPa}\right)$, and M2$2\left(\sigma_{\mathrm{d}} \neq 0 \mathrm{MPa}, p=3 \mathrm{MPa}\right)$. Meanwhile, the M3 group was used to investigate the propagation laws of blast-induced cracks in pre-cracked specimens with different angles in the same stress field (the experimental model is shown in Fig. 1 (b)). Pre-cracks with length of $50 \mathrm{~mm}$ were observed at the center. The angles between crack and initial tensile stress were divided into $90^{\circ}, 45^{\circ}$, and $0^{\circ}$ groups, and circular holes with diameter of $6 \mathrm{~mm}$ were set at the center. Under

the same initial tensile stress $(p=3 \mathrm{MPa})$, specimens were numbered M3-0 ( $\left.\theta=90^{\circ}\right)$, M3-1 ( $\left.\theta=45^{\circ}\right)$, and M3-2 $\left(\theta=0^{\circ}\right.$ ) on the basis of their different pre-crack angles.

\subsection{Experimental system}

The experimental method of caustics [26] was important in recording crack propagation data (length, velocity, and dynamic stress intensity factor). For a plate containing cracks, caustic spots were generated at the crack tip. The dynamic stress intensity factor of crack tip could be expressed as follows:

$$
K_{\mathrm{I}}^{d}=\frac{2 \sqrt{2 \pi}}{3 z_{0} d_{\mathrm{eff}} c g^{5 / 2}} \cdot D_{\max }^{5 / 2}
$$

$K_{\mathrm{II}}^{d}=\mu \cdot K_{\mathrm{I}}^{d}$

where $D_{\max }$ is the maximum caustic diameter; $z_{0}$ is the distance from the specimen to the reference plane; $g$ is the numerical constant; $d_{\text {eff }}$ is the specimen thickness; $c$ is the optical constant of specimen; $\mu$ is the proportionality coefficient.

For a plate with circular holes, stress concentration occurred around the holes under the action of static stress. The maximum length of caustic spots was $D$, and the principal stress difference was calculated as follows:

$$
P=\frac{1}{12 \times(2.67)^{4} z_{0} c d_{\mathrm{eff}} R^{2}} D^{4}
$$

where $P$ is the horizontal stress; $R$ is the radius of circular holes; $D$ is the length of dumbbell-shaped caustic spot. $d_{\text {eff }}$, $c$, and $z_{0}$ are constants, and principal stress difference is determined through $D$.

The caustic experimental system combining laser and high-speed camera was used in the present study. This system included laser, beam expander, field lens, loading device, high-speed camera, and computer (Fig. 2). The 
Liyun Yang, Chen Huang, Chenxi Ding, Huanzhen Xie and Yuh J. Chao/

Journal of Engineering Science and Technology Review 13 (1) (2020) 193 - 203

computer system was used to collect caustic pictures. The initial static load in the experiment was applied by an MTS testing machine (Fig. 3). A slab tensile fixture was used; one end of the planar specimen was fixed, and the other end was applied with vertical uniaxial tensile load. In the experimental process, MTS testing machine was used to record tensile load amplitude. The blasting load was applied through explosion of a self-made spherical charge of lead azide. Explosive payload was $100 \mathrm{mg}$. Subsequently, the charging structure was coupled; detonation line was placed in boreholes in the charging process and connected to a high-voltage pulse initiator. Finally, the explosive was detonated using electric spark generated by the initiator.

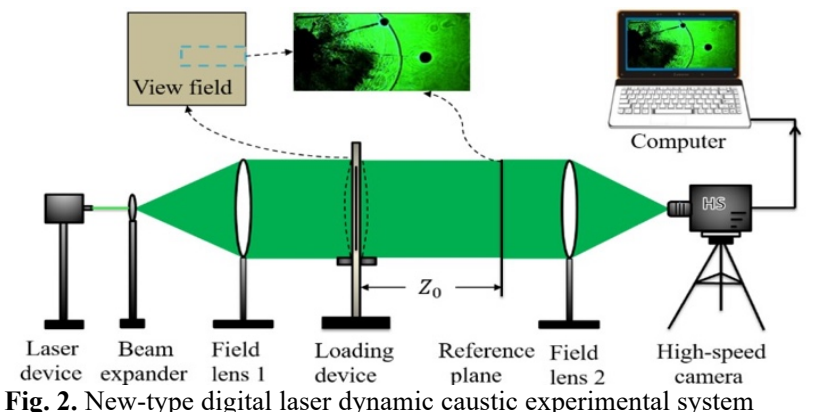

Fig. 2. New-type digital laser dynamic caustic experimental system

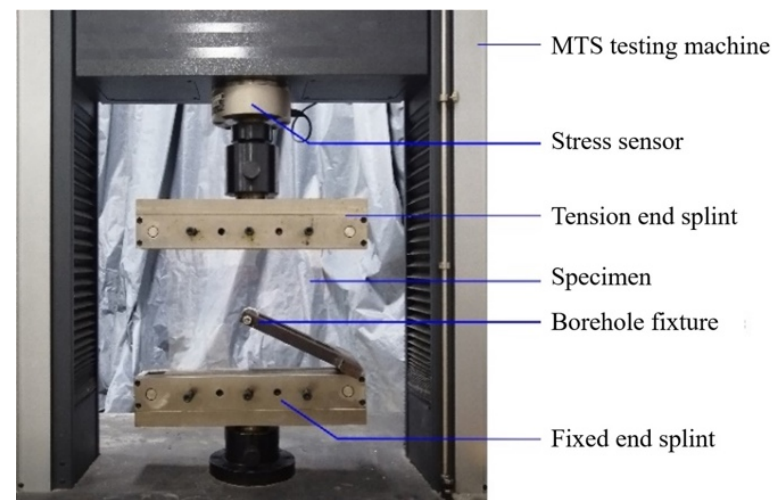

\section{Experimental results and analysis}

\subsection{Specimen stress analysis}

4.1.1 Stress distribution around circular holes under dynamic-static stress field

Assuming that the blasted medium is an infinite plate, a circular hole with radius of $r$ can be observed in the center of this plate. Equivalent blasting stress $\sigma_{\mathrm{d}}$ is applied inside the circular hole, and initial uniformly distributed tensile stress $p$ acts in the vertical direction of the plate (Fig. 4 (a)).

Under the action of initial tensile stress $p$ (Fig. 4 (b)), the circumferential stress on the inner wall of circular hole can be expressed as follows:

$\sigma_{\theta 1}=p(1-2 \cos 2 \theta)$

where $\sigma_{\theta 1}$ is the circumferential stress of the hole wall under the action of initial tensile stress $p ; \theta$ is the circumferential coordinate in the polar coordinate system.

Under the action of blasting stress $\sigma_{\mathrm{d}}$ (Fig. 4 (c)), the circumferential stress on the inner wall of circular hole can be expressed as follows:

$\sigma_{\theta 2}=\sigma_{\mathrm{d}}$

where $\sigma_{\theta 2}$ is the circumferential stress on the hole wall only under the action of blasting stress $\sigma_{\mathrm{d}}$.

According to the superposition principle in the linear elastic mechanics, the specimen is under joint action of initial tensile stress $p$ and blasting stress $\sigma_{\mathrm{d}}$. The circumferential stress on the inner wall of circular hole can be expressed as follows:

Fig. 3. Dynamic-static combined loading system

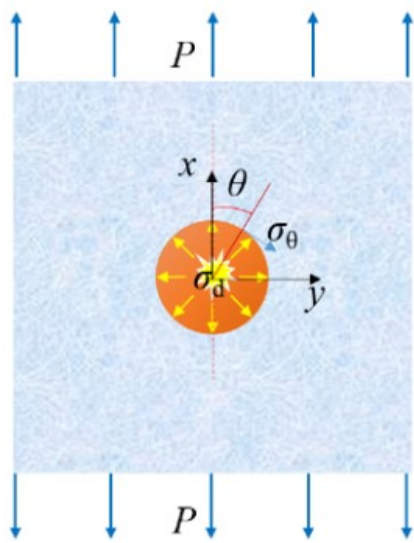

(a)
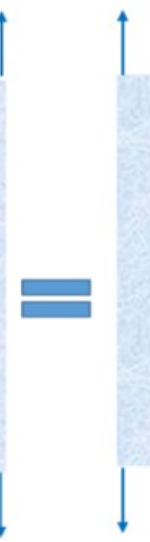

Fig. 4. Schematic of circular borehole in superposed stress field

$\sigma_{\theta}=\sigma_{\theta 1}+\sigma_{\theta 2}=p(1-2 \cos 2 \theta)+\sigma_{\mathrm{d}}$

where $\sigma_{\theta}$ is the circumferential stress on the hole wall under the action of combined stress field.

Given the axisymmetric structure of the specimen, the circumferential stress graph of the inner wall of circular hole under the action of dynamic-static combined stress field with $\theta \in[0, \pi]$ is drawn. When $\theta=90^{\circ}$, circumferential stress $\sigma_{\theta}$ on the inner wall of circular hole has the maximum value (Fig. 5). Therefore, under the joint action of initial tensile stress $p$ and blasting stress $\sigma_{\mathrm{d}}$, the inner wall of circular hole can experience failure easily at this position. 
Liyun Yang, Chen Huang, Chenxi Ding, Huanzhen Xie and Yuh J. Chao/

Journal of Engineering Science and Technology Review 13 (1) (2020) 193 - 203

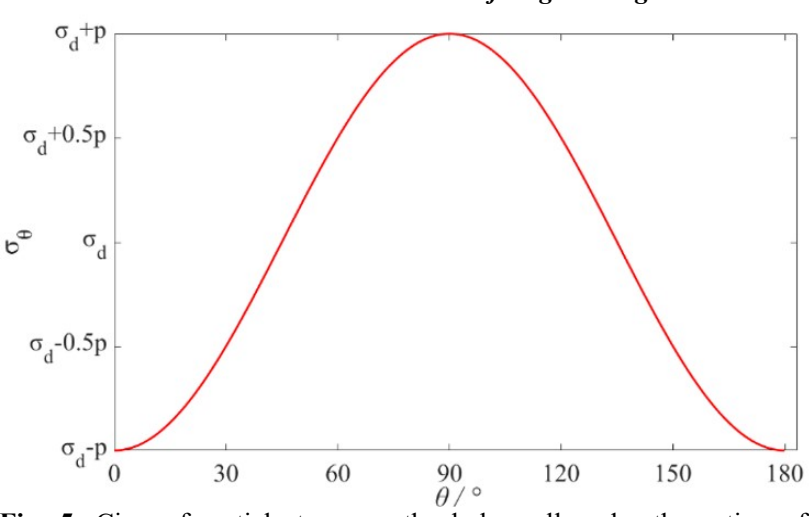

Fig. 5. Circumferential stress on the hole wall under the action of dynamic-static combined stress field

\subsubsection{Analysis of stress concentration at crack tip and} crack deflection angle under dynamic-static stress field

For a crack $2 a$ in length, uniformly distributed tensile stress $p$ acts in the vertical direction of the plate, and blasting gas pressure $\sigma_{\mathrm{g}}$ acts on the crack surface. To simplify the blasting model, the blasting gas pressure $\sigma_{\mathrm{g}}$ is equivalent to quasi-static stress (linear stress load) which acts on the crack surface (Fig. 6 (a)).
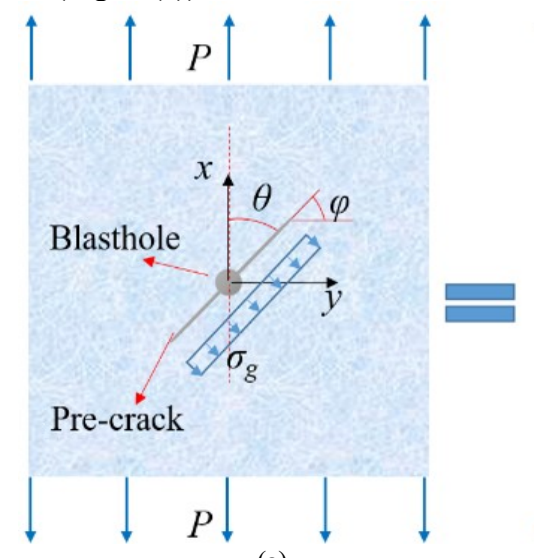

(a) (b)

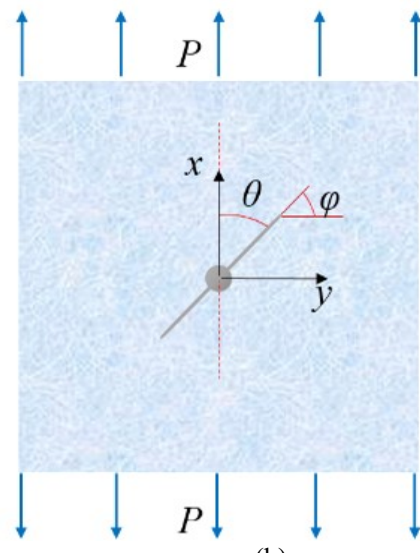

Under the action of initial tensile stress $p$ (Fig. 6 (b)), the stress intensity factor at crack tip can be expressed as follows:

$\left\{\begin{array}{l}K_{\mathrm{I}}=\sigma_{\theta} \sqrt{\pi a}=p \sqrt{\pi a} \sin ^{2} \theta \\ K_{\mathrm{II}}=\tau_{\theta} \sqrt{\pi a}=p \sqrt{\pi a} \sin \theta \cos \theta\end{array}\right.$

where $K_{\mathrm{I}}$ is the mode I stress intensity factor, and $K_{\text {II }}$ is the mode II stress intensity factor.

Under the action of equivalent dynamic stress $\sigma_{\mathrm{g}}$ (linear stress load; Fig. 6 (c)), the dynamic stress intensity factor generated by crack tip is expressed as follows on the basis of the Stress Intensity Factor Handbook [27]:

$$
\left\{\begin{array}{l}
K_{\mathrm{I}}^{\mathrm{d}}=\sigma_{\mathrm{g}} \sqrt{\pi a} \\
K_{\mathrm{II}}^{\mathrm{d}}=0
\end{array}\right.
$$

Fig. 6. Pre-crack graphs in superposed stress field

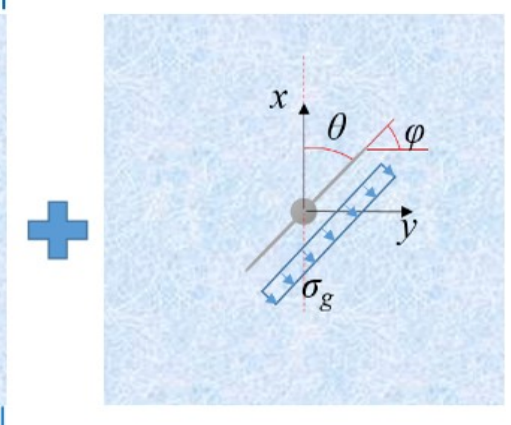

On the basis of the elastic fracture mechanics, stress field at crack tip can be solved through linear superposition of single load action. Superposing stress intensity factors from (7) and (8), the crack initiation criterion under the dynamic-static combined stress field can be obtained as in accordance with the MTS crack initiation criterion:

$$
\begin{aligned}
& \left(p \sqrt{\pi a} \sin ^{2} \theta+\sigma_{\mathrm{g}} \sqrt{\pi a}\right) \sin \varphi+ \\
& p \sqrt{\pi a} \sin \theta \cos \theta(3 \cos \varphi-1)=0
\end{aligned}
$$

where $\varphi$ is the crack initiation angle.

Assuming that $n=\sigma_{\mathrm{g}} / p$, the following can be obtained:

$$
\left(\sin ^{2} \theta+n\right) \sin \varphi+\sin \theta \cos \theta(3 \cos \varphi-1)=0
$$

The relation graph between crack initiation angle $\varphi$ and tilt angle $\theta$ is drawn. When crack tile angle $\theta$ is certain, the greater the $n$ and the smaller the crack initiation angle $\varphi$, indicating that the ratio of blasting gas pressure to initial tensile stress influences the crack deflection angle (Fig. 7).

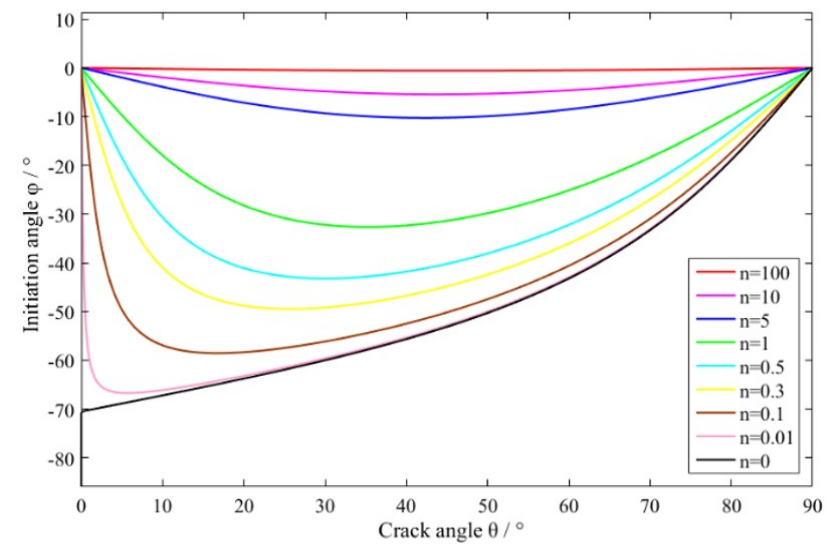

Fig. 7. Relation graph between crack initiation angle $\varphi$ and tilt angle $\theta$

\subsection{Propagation behavior of blast-induced main cracks under different static tensile stresses}

\subsubsection{Stress concentration around borehole}

As shown in Fig. 8, an evident stress concentration zone was generated around circular hole under vertical tensile load. In addition, dumbbell-shaped caustic spots were formed, and a 
Liyun Yang, Chen Huang, Chenxi Ding, Huanzhen Xie and Yuh J. Chao/

Journal of Engineering Science and Technology Review 13 (1) (2020) 193 - 203

strong tensile stress concentration zone was generated at the left and right ends of the hole wall. As the tensile load increased, caustic spots were enlarged, indicating that the stress concentration degree of circular hole was gradually enhanced. The characteristic lengths $D$ of dumbbell-shaped caustic spots under different loads were measured and

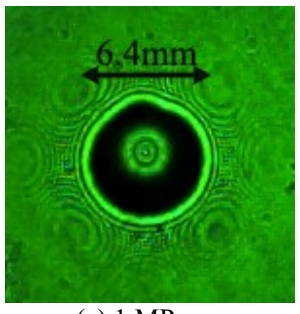

(a) $1 \mathrm{MPa}$

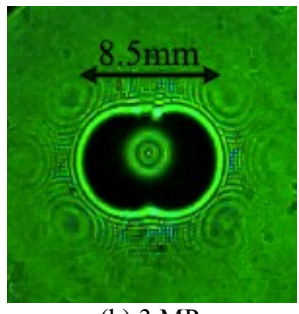

(b) $3 \mathrm{MPa}$
Fig. 8. Caustic spots around the circular hole under different tensile loads

Table 2. Static caustic results around the circular hole

\begin{tabular}{c|c|c|c|c}
\hline$p(\mathrm{MPa})$ & 1 & 3 & 6 & 9 \\
\hline Theoretical result $D(\mathrm{~mm})$ & 6.2 & 8.3 & 9.8 & 10.9 \\
Experimental result $D(\mathrm{~mm})$ & 6.4 & 8.5 & 9.7 & 10.5 \\
\hline
\end{tabular}

\subsubsection{Specimen failure modes}

The photos of specimens in the M1 group after blasting are shown in Fig. 9. The quantities of blast-induced cracks generated in four specimens were identical. As the tensile stress $p$ increased, the crushing degree nearby the borehole was enhanced, and the propagation lengths and distribution characteristics of main cracks in distant zones in the borehole were different. Crack propagation caused by single blasting stress existed in specimens M1-0. The propagation length of main cracks was short, and crack distribution was uniform. Under the action of blasting load, many small cracks were generated in nearby zone of the borehole. In distant zones in the borehole, main cracks with great propagation length were formed, presenting "*” shape, because high-pressure jet of blasting gas acted upon the hole wall, enlarging tensile stress of cracks and driving crack propagation. Meanwhile, blasting stress wave experienced

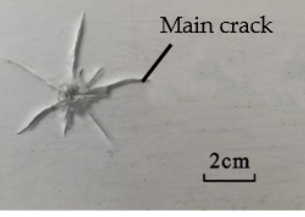

(a) $\mathrm{M} 1-0(\mathrm{p}=0 \mathrm{MPa})$

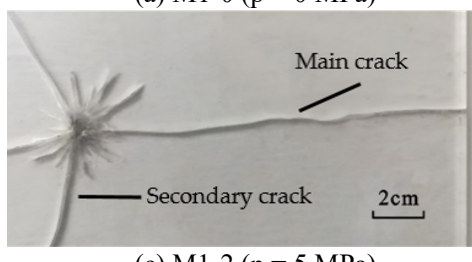

(c) $\mathrm{M} 1-2(\mathrm{p}=5 \mathrm{MPa})$

Fig. 9. Crack distribution patterns around borehole in the M1 group

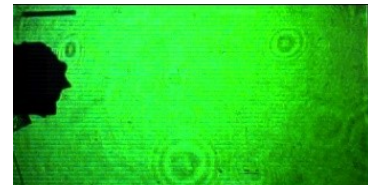

$0 \mu \mathrm{s}$

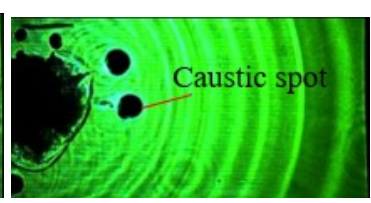

$60 \mu \mathrm{s}$ recorded. Such lengths were compared with the results calculated through theoretical formula of caustic (Table. 2). The experimental result had a certain error with theoretical result, but it basically reflected the change of stress concentration degree in the circular hole.

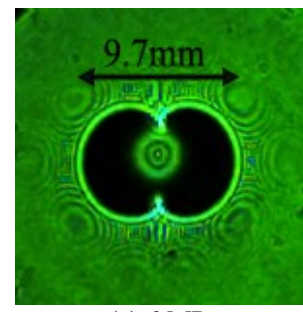

(c) $6 \mathrm{MPa}$

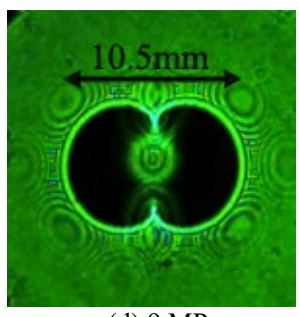

(d) $9 \mathrm{MPa}$ reflection and diffraction at crack tip to aggravate tensile stress concentration and drive crack propagation.

The longest main cracks running through specimens (M1-1, M1-2, and M1-3) were generated in the direction of the maximum tensile stress. Such cracks were greater than propagation lengths of cracks in specimen M1-0, indicating that crack propagation length would increase with initial tensile stress $p$. Secondary cracks were also distributed at two sides of the borehole, and they were lengthened with the initial tensile stress $p$. Specimens M1-1, M1-2, and M1-3 were subjected to dual effects of tensile load and blasting load. Under the action of initial tensile stress, stress concentration would take place around the circular hole, a large tensile stress zone would be generated along the left and right sides of the hole wall, and compressive stress would be generated above and below the borehole. Blasting stress was applied. Under the joint action of initial tensile stress and blasting stress, cracks would first propagate toward the maximum principal stress zone, and the longest main crack was generated in the direction of maximum tensile stress, in which initial tensile stress changed the distribution characteristics of blast-induced cracks.

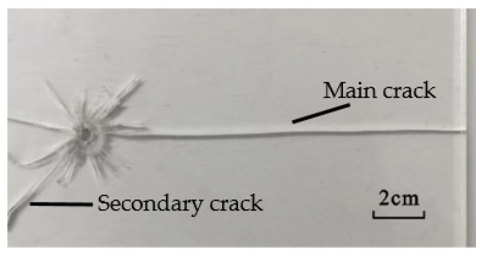

(b) $\mathrm{M} 1-1(\mathrm{p}=2.5 \mathrm{MPa})$

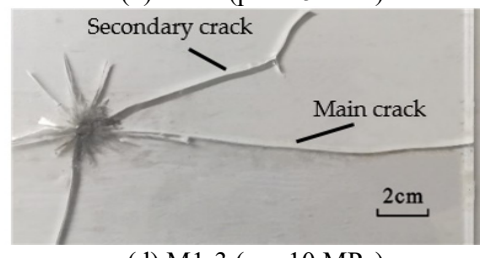

(d) $\mathrm{M} 1-3(\mathrm{p}=10 \mathrm{MPa})$

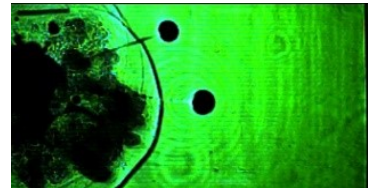

$120 \mu \mathrm{s}$

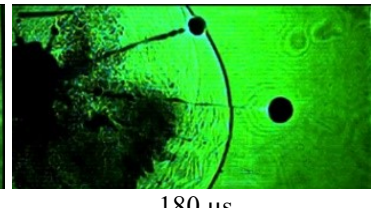

$180 \mu \mathrm{s}$ 


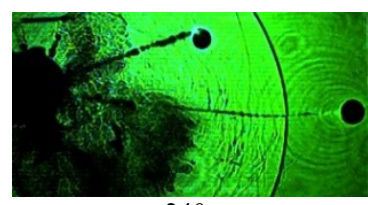

$240 \mu \mathrm{s}$

Fig. 10. Caustic line of specimen M1-3

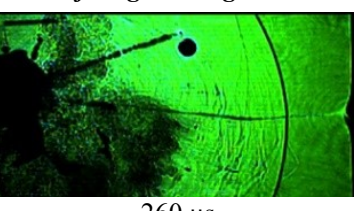

The blasting failure process of specimen M1-3 shot by a high-speed camera is shown in Fig. 10. After the specimen M1-3 was blast, caustic spots started appearing first in horizontal direction. Subsequently, caustic spots presented approximately linear propagation under the action of blasting stress wave and blasting gas. The sizes of the caustic spots did not experience any major change from crack initiation until run-through, and their shapes were primarily mode I. For specimens M1-0, M1-1, and M1-2, caustic spots presented mode I shape in the propagation of main cracks, and the propagation path was quite straight. However, caustic spots of specimen M1-0 were continuously diminished from crack initiation until crack arrest. Caustic spots of specimens M1-1 and M1-2 were first reduced and then enlarged during propagation. Under the action of blasting load, the energy at crack tip in specimen M1-0 was gradually reduced, stress concentration degree was gradually lowered, and diameter of caustic spots was reduced. However, M1-1 and M1-2 specimens primarily experienced the action of blasting load in the initial phase of crack propagation; the diameter of caustic spots was reduced and then enlarged again due to joint action of initial tensile stress and reflected wave in the later phase.

\subsubsection{Crack propagation behavior}

As shown in Fig. 11, the crack propagation and displacement after the specimen was detonated without initial tensile load were smaller than that with initial tensile load, manifesting that initial tensile load could increase the propagation length of blast-induced cracks. As the tensile stress $p$ increased, the continuity of displacement and propagation of main cracks were enhanced because the order of magnitude of tensile load was approximate to that of blasting load. In addition, as the initial tensile load increased, the propagation velocity of main cracks was gradually elevated, indicating that initial tensile stress $p$ accelerated crack propagation (Fig. 12).

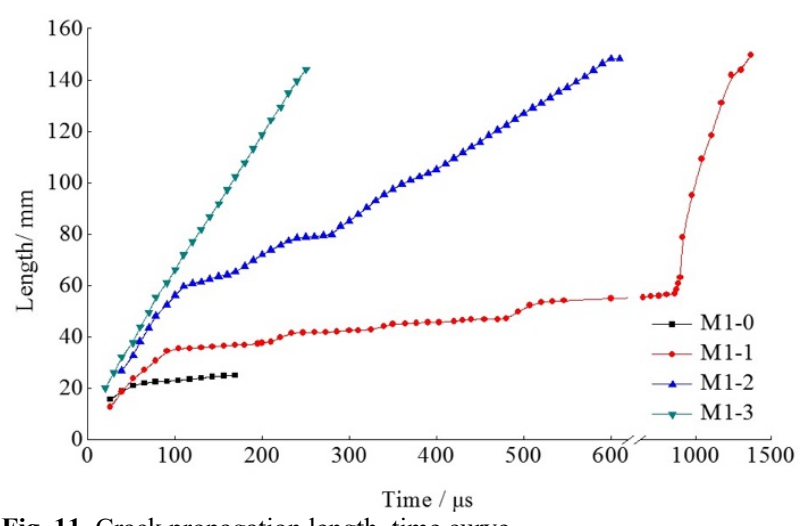

Fig. 11. Crack propagation length-time curve

\subsubsection{Crack stress intensity factor}

Based on the stress intensity factor-time curve at crack tip (Fig. 13), the peak value of stress intensity factor of specimen M1-0 was the minimum, and the stress intensity factor curves of specimens M1-0 to M1-3 rose in succession, indicating that the greater the initial tensile stress, the higher the stress concentration degree generated at main crack tip, and crack initiation and propagation will be easy. The stress intensity factors of specimens M1-0 to M1-3 reached peak values at $26 \mu \mathrm{s}, 39 \mu \mathrm{s}, 60 \mu \mathrm{s}$ and $110 \mu \mathrm{s}$, respectively, being $1.18 \mathrm{MPa} \cdot \mathrm{m}^{1 / 2}, 1.96 \mathrm{MPa} \cdot \mathrm{m}^{1 / 2}, 2.39 \mathrm{MPa} \cdot \mathrm{m}^{1 / 2}$ and 2.67 $\mathrm{MPa} \cdot \mathrm{m}^{1 / 2}$. Therefore, the time when specimens M1-0 to M1-3 reached the maximum peak value was successively lengthened, indicating that initial tensile stress could postpone the time when the stress intensity factor reached the maximum peak value. Moreover, the greater the initial stress, the faster the attenuation of stress intensity factor.

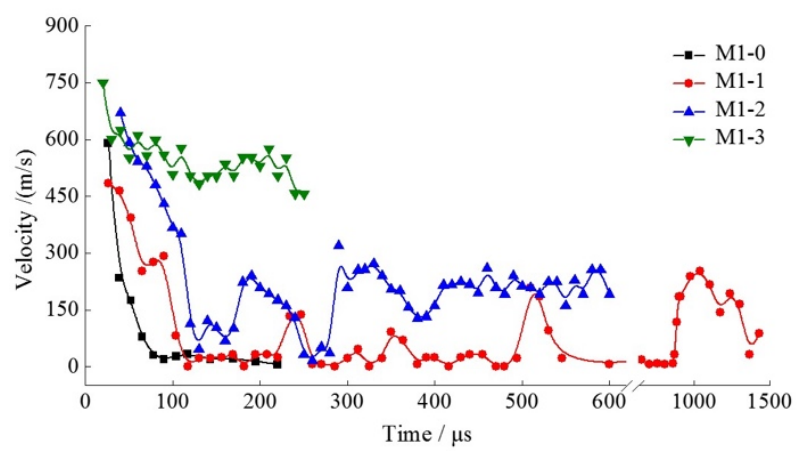

Fig. 12. Crack propagation velocity-time curve

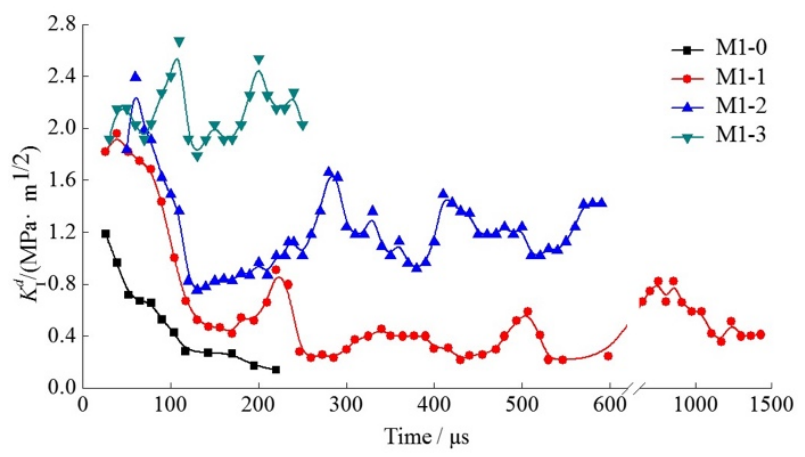

Fig. 13. Dynamic stress intensity factor-time curve at crack tip

\section{$4.345^{\circ}$ oblique pre-cracks under different tensile stresses}

\subsubsection{Specimen failure modes}

The failure modes of specimen M2-0 when only initial tensile stress $p$ was applied are shown in Fig. 14 (a). Under the load of $p=6.5 \mathrm{MPa}$, crack initiation occurred at precrack tip under the action of shear force along direction $\varphi=53^{\circ}$, which was nearly identical with the theoretical result in Section 4.1 (Fig. 7). Fig. 14 (b) and (c) show the post- blasting morphologies of specimens M2-1 and M2-2. From the crack distribution after blasting, a crack zone was observed around the borehole combined with many small cracks, which were the result of dual actions of blasting stress wave and blasting gas. A long main crack and short secondary crack were generated at pre-crack tip, and cracks basically presented symmetric distribution. The blastinduced main cracks at upper right were the study objects. First, for specimen M2-1, blast-induced main crack presented linear propagation along the direction of original crack, indicating that under the action of blasting stress, the crack propagation was mode I propagation. For specimen M2-2, the blast-induced main crack presented linear propagation along the direction of original crack and then clockwise downward $\varphi=33^{\circ}$ propagation. In the end, the blast-induced main crack was propagated clockwise downward by $\varphi=47^{\circ}$ towards the specimen boundary. 
Comparing the crack propagation paths of specimens in the two groups, the blast-induced main crack in specimen M2-2 experienced major deflection downward clockwise, indicating that under the action of initial tensile stress $p$, the blast-induced main crack deflected towards the direction perpendicular to tensile stress.

As shown in caustic pictures of specimens M2-0, M2-1, and M2-2, mixed mode I-II caustic spots appeared in specimen M2-0 in crack initiation phase. After crack initiation, caustic spots were turned from mode I-II into mode I, whereas the size of caustic spots almost did not change, and the propagation path was straight and flat, indicating mode I as failure. After blasting of specimen M21 , stress concentration appeared at crack tip, crack initiation took place, and cracks were propagated forward. Caustic spots were gradually reduced with time, the propagation path was straight and flat, and the shape of caustic spots was basically approximately presented linear propagation. As the blasting stress declined, mixed mode I-II caustic spots appeared, the crack experienced major deflection, and caustic spots were first reduced and then gradually enlarged with time, indicating that in the dynamic-static combined stress field, initial tensile stress was the primary factor for oblique cracks to generate mode II failure.

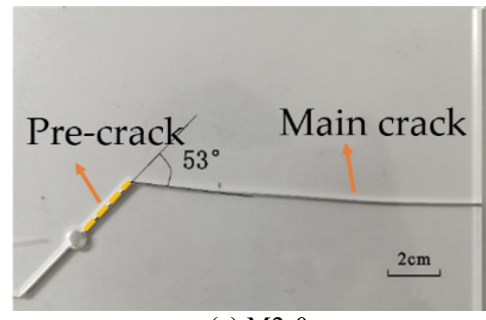

(a) M2-0

Fig. 14. Crack distribution forms around borehole in the M2 group

\subsubsection{Crack propagation behavior}

The propagation length-time curve and velocity-time curve of the main crack are shown in Figs. 15 and 16, respectively. Restricted by field of view of the camera, Figs. 15 and 16 only display the main crack propagation data of specimen M2-2 before $210 \mu \mathrm{s}$. Although the entire process of main crack propagation of specimen M2-2 was recorded, the experimental analysis could be completed on the basis of the existing data. As shown in Fig. 15, the main crack of specimen M2-1 stopped propagation at $195 \mu$ s, and its length was $69.2 \mathrm{~mm}$. However, at $210 \mu \mathrm{s}$, the main crack length of specimen M2-2 was $107.1 \mathrm{~mm}$, indicating that the main crack length of specimen M2-2 was greater than that of specimen M2-1. In addition, tensile stress could increase the propagation length of $45^{\circ}$ oblique crack under the action of blasting stress.

The main crack propagation velocity of specimens M2-1 and M2-2 rapidly increases after crack initiation, reaching maximum values of $690.5 \mathrm{~m} / \mathrm{s}$ and $654.9 \mathrm{~m} / \mathrm{s}$ at $45 \mu$ and 56 $\mu$ s, respectively (Fig. 16). In comparison with specimen M21, specimen M2-2 bore additional tensile stress, which resulted in high-energy accumulation at pre-crack of specimen M2-2. Meanwhile, the early-stage crack propagation velocity of specimen M2-2 was evidently higher than that of specimen M2-1. For better analysis of experimental data, the difference between the first peak value and the first valley value on the curve was defined as attenuation amplitude, and the corresponding time difference was defined as attenuation time interval. Compared with specimen M2-1, the attenuation amplitude of main crack propagation velocity and time interval of M2-2 were high. In the later crack propagation phase, the main crack propagation velocity of specimen M2-1 was reduced until crack arrest, and the main crack propagation velocity of specimen M2-1 was lower than that of specimen M2-2. Overall, tensile stress could also elevate the propagation velocity of $45^{\circ}$ oblique crack under the action of blasting stress. Tensile stress could postpone the attenuation time of propagation velocity of $45^{\circ}$ oblique crack and enlarge the attenuation amplitude of propagation velocity of $45^{\circ}$ oblique crack.

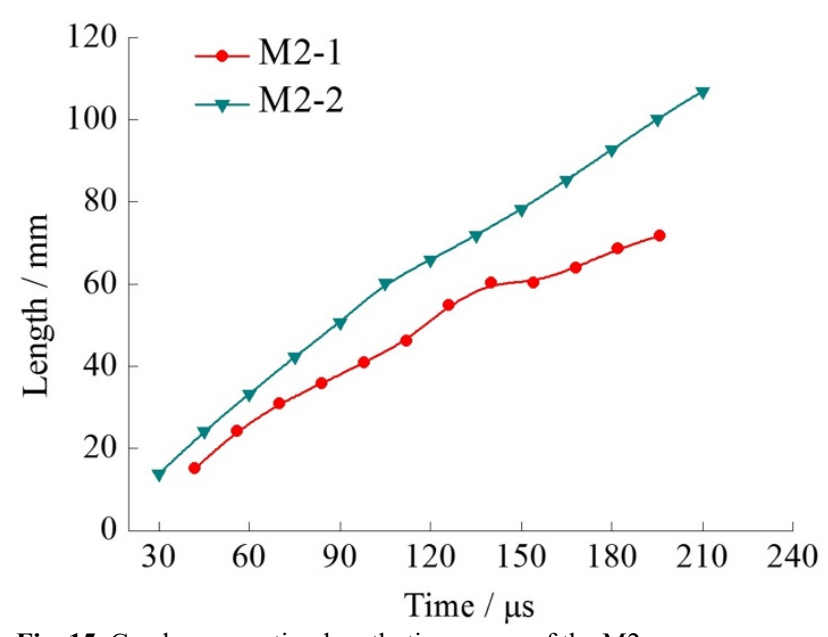

Fig. 15. Crack propagation length-time curve of the M2 group

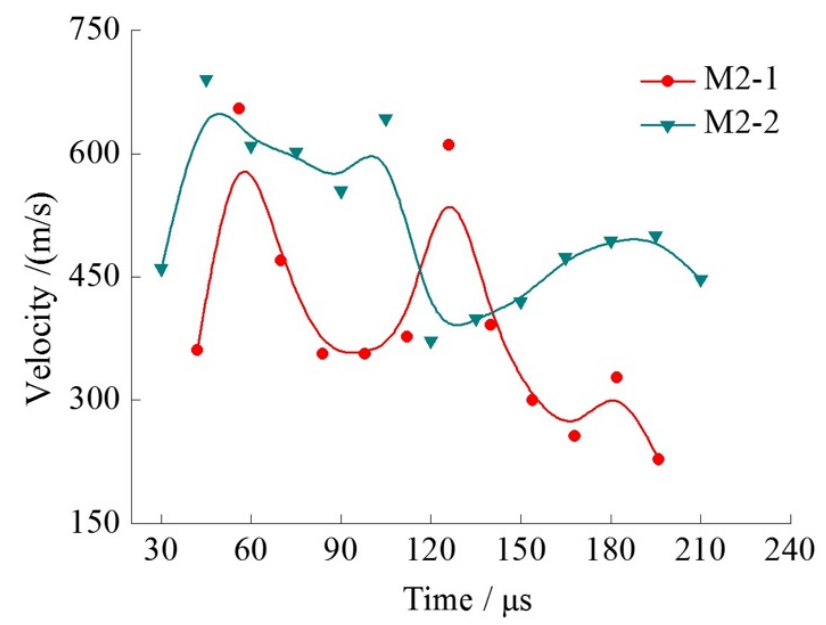

Fig. 16. Crack propagation velocity-time curve of the M2 group

\subsubsection{Crack stress intensity factor}

The time-dependent change curve of dynamic stress intensity factors of the M2 group is shown in Fig.17, and similar laws to velocity curve in Fig. 16 are manifested. Before $120 \mu \mathrm{s}$, the dynamic stress intensity factor of specimen M2-1 was smaller than that of specimen M2-2, 
Liyun Yang, Chen Huang, Chenxi Ding, Huanzhen Xie and Yuh J. Chao/

Journal of Engineering Science and Technology Review 13 (1) (2020) 193 - 203

indicating that in the initial blasting phase, the main crack of specimen M2-2 could be more easily generated and propagated. The dynamic stress intensity factor of specimen M2-1 reached the first peak value $0.65 \mathrm{MPa} \cdot \mathrm{m}^{1 / 2}$ at $45 \mu \mathrm{s}$. Subsequently, M2-1 curve fluctuated and finally reached the first valley value $0.38 \mathrm{MPa} \cdot \mathrm{m}^{1 / 2}$ at $90 \mu \mathrm{s}$. Therefore, the attenuation time interval of dynamic stress intensity factor of the main crack of specimen M2-1 was $45 \mu$ s while its attenuation amplitude was $0.27 \mathrm{MPa} \cdot \mathrm{m}^{1 / 2}$. For specimen $\mathrm{M} 2-2$, the curve reached the first peak value of 0.87 $\mathrm{MPa} \cdot \mathrm{m}^{1 / 2}$ at $45 \mu \mathrm{s}$ and the first valley value of 0.37 $\mathrm{MPa} \cdot \mathrm{m}^{1 / 2}$ at $120 \mu \mathrm{s}$ in the end. Correspondingly, the specimen M2-2 reached the first peak value of 0.87 $\mathrm{MPa} \cdot \mathrm{m}^{1 / 2}$ at $45 \mu \mathrm{s}$ and the first valley value of 0.37 $\mathrm{MPa} \cdot \mathrm{m}^{1 / 2}$ in the end. The attenuation time interval of the dynamic stress intensity factor in specimen M2-2 main crack was $75 \mu \mathrm{s}$ while its attenuation amplitude was 0.50 $\mathrm{MPa} \cdot \mathrm{m}^{1 / 2}$. The abovementioned analysis indicated that tensile stress could increase the attenuation time interval and attenuation amplitude of stress intensity factor of $45^{\circ}$ oblique crack. In the initial blasting phase, the stress intensity factor at main crack tip increased with the tensile stress.

\subsection{Pre-cracks with different angles}

\subsubsection{Specimen failure modes}

The failure modes of specimens M3-0, M3-1, and M3-2 are shown in Fig. 18. After the blasting, long main cracks were generated along the pre-crack direction of the three-group specimens. As the blasting crack propagation of pre-cracks with different angles in the same stress field was experimentally studied in this group, the main crack at precrack tip was selected as the study object. Blast-induced main cracks of specimens M3-0 and M3-2 presented approximately linear propagation along the pre-crack direction, and the blast-induced main crack of specimen M31 deflected downward clockwise along the direction of original pre-crack, indicating that in the initial tensile stress and blasting stress combined stress field, the pre-crack angle would influence the deflection in crack propagation. Straight cracks (collinear with direction of maximum tensile stress or perpendicular to the direction of maximum tensile stress) did not experience deflection. Oblique cracks would go through deflection along the direction of the maximum tensile stress

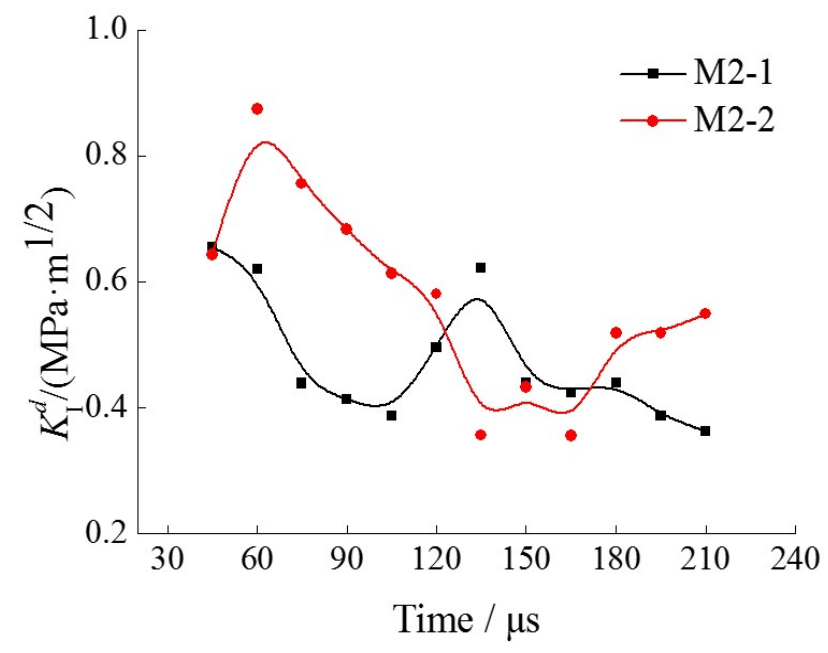

Fig. 17. Dynamic stress intensity factor-time curve at crack tip

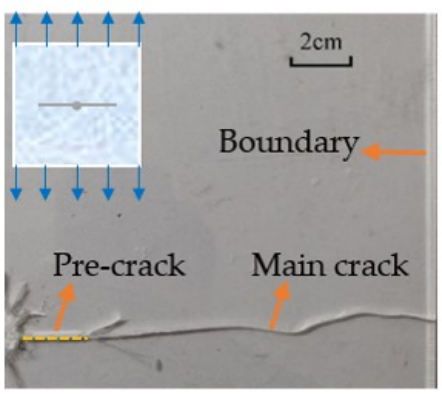

(a) M3-0 $\left(\theta=90^{\circ}\right)$

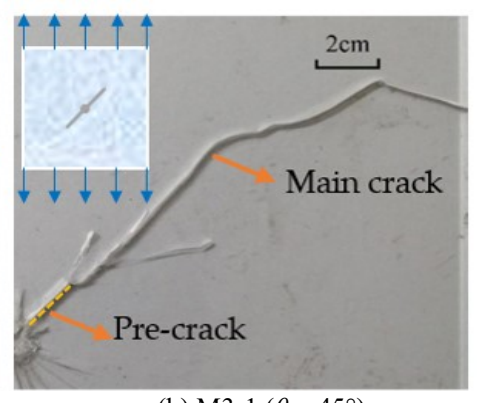

(b) $\mathrm{M} 3-1\left(\theta=45^{\circ}\right)$

Fig. 18. Crack distribution forms around borehole in the M3 group

\subsubsection{Crack propagation behavior}

In the M3 group, the main cracks of specimens M3-0 and M3-1 ran through the specimens, and the propagation path of the main crack in specimen M3-1 was crooked. Therefore, the maximum propagation length of the blast-induced main crack could not be measured. However, the propagation lengths of main cracks in specimens M3-0 and M3-1 were both greater than that of specimen M3-2 (Fig. 18). The influence of tensile stress on crack propagation length caused by blasting in this group would not be investigated.

Fig. 19 shows the change in crack propagation velocity in the M3 group before $211 \mu \mathrm{s}$. The main crack propagation velocity fluctuated. In the early crack propagation phase, the first peak velocity of specimen M3-1 was slightly lower than that of specimen M3-0, and the peak velocity of specimen M3-2 was the minimum. The results showed that under the same tensile stress and blasting stress, the enlargement of crack angle would result in rapid main crack propagation. For crack velocity in specimens M3-0, M3-1, and M3-2, their attenuation amplitudes were $418 \mathrm{~m} / \mathrm{s}, 343.9 \mathrm{~m} / \mathrm{s}$, and $278.9 \mathrm{~m} / \mathrm{s}$, respectively, and their attenuation time intervals were $90 \mu \mathrm{s}, 75 \mu \mathrm{s}$ and $55 \mu \mathrm{s}$, respectively. As the blasting stress was weakened, the attenuation time interval of main crack velocity in specimen M3-0 was the maximum, whereas that of specimen M3-2 was the minimum. In addition, the velocity attenuation amplitudes of specimens M3-0, M3-1, and M3-2 were reduced successively. In the later crack propagation phase, the main crack velocity of specimen M3-1 was higher than that of specimen M3-0, which was due to slow attenuation of main crack velocity in specimen M3-0. As the main crack velocity of specimen M3-1 was closer to that of specimen M3-0, the main crack velocity with pre-crack angle of $45^{\circ}-90^{\circ}$ slightly changed in the superposed stress field. Furthermore, the enlargement of pre-crack angle could not elevate the crack velocity infinitely. Overall, the main crack velocity was accelerated with the pre-crack angle, and the enlargement of pre-crack 
angle could facilitate attenuation amplitude and time interval of crack propagation velocity.

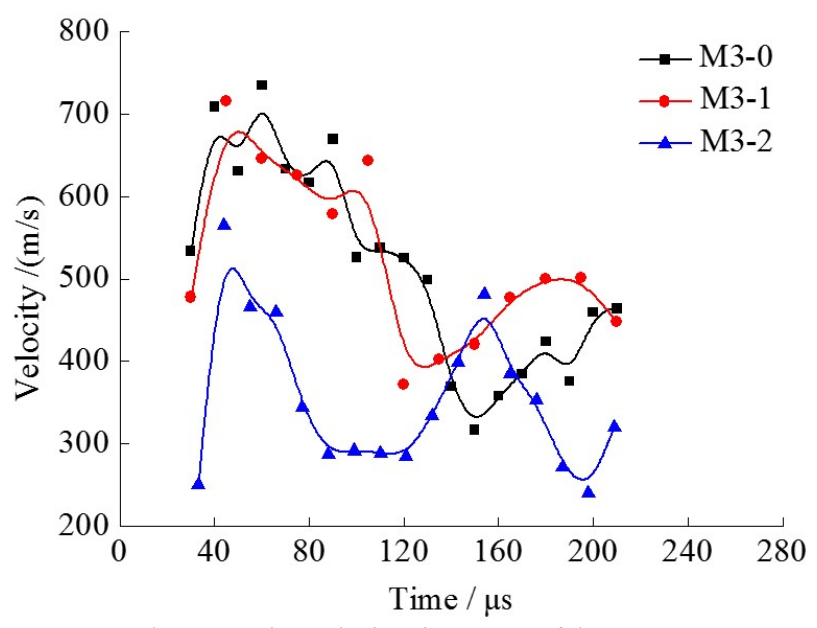

Fig. 19. Crack propagation velocity-time curve of the M3 group

\subsubsection{Crack stress intensity factor}

The time-dependent change curve of dynamic stress intensity factor is shown in Fig. 20. In the early crack propagation phase, the stress intensity factors at crack tip of specimens M3-2 to M3-0 were successively increased. The results showed that the dynamic stress intensity factor increased with the pre-crack angle. In addition, the stress intensity factor was continuously attenuated with the crack propagation. For specimens M3-0, M3-1, and M3-2, the attenuation time intervals of their stress intensity factors were $120 \mu \mathrm{s}, 75 \mu \mathrm{s}$, and $44 \mu \mathrm{s}$, respectively, and their attenuation amplitudes were $0.656 \mathrm{MPa} \cdot \mathrm{m}^{1 / 2}, 0.517$ $\mathrm{MPa} \cdot \mathrm{m}^{1 / 2}$ and $0.362 \mathrm{MPa} \cdot \mathrm{m}^{1 / 2}$, respectively. Similar to the crack propagation velocity laws, the attenuation amplitude and time interval of dynamic stress intensity factor were remarkably increased with the pre-crack angle.

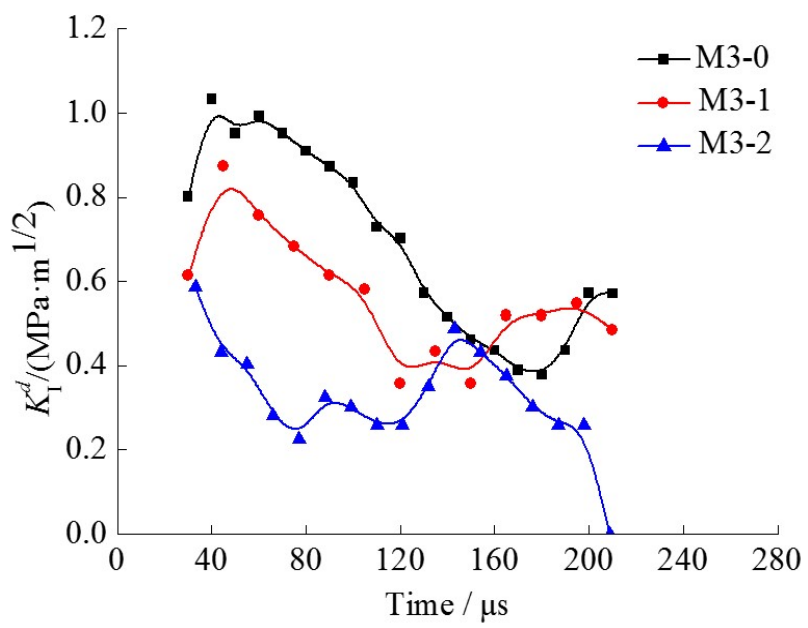

Fig. 20. Dynamic stress intensity factor-time curve at crack tip in the M3 group

\section{Conclusions}

The deflection laws of blast-induced main cracks under the action of static tensile stress were summarized through theoretical analysis to investigate the blast-induced crack propagation behavior under the joint action of blasting stress and static tensile stress. The model experiment was carried out to study the initiation and propagation behavior of blastinduced main cracks in the medium under the action of static tensile stress, blasting stress, and failure mode. The following conclusions were drawn:

(1) Static tensile stress changes the blast-induced main crack distribution characteristics in circular borehole, and the longest main crack is generated where the circumferential tensile stress is the maximum on the wall of borehole.

(2) Dynamic mechanical parameters of the main crack like propagation velocity, length, and dynamic stress intensity factor increase with static tensile stress. Moreover, the main crack propagation mode is gradually turned from mode I into mixed mode I-II under the static stress, and the propagation path is deflected.

(3) Dynamic stress intensity factor of the main crack is increased with the included angle between pre-crack and tensile stress. In addition, the enlargement of this included angle can significantly postpone the attenuation time of main crack velocity and dynamic stress intensity factor in the superposed stress field and enlarge their attenuation amplitudes.

In summary, caustic theory and model experimental method were combined in the present study to subtly investigate dynamic mechanical behavior of blast-induced cracks under the coupling action of tensile stress and blasting stress. Physical quantities, such as propagation velocity at crack tip, propagation length, and dynamic stress intensity factor, were quantitatively analyzed. Moreover, the influence of tensile stress field on blasting fracture mechanism was acquired to lay a foundation for a further study of dynamic behavior of blast-induced cracks under complicated load action. However, restricted by the field of view of the camera, crack arrest was not deeply explored in the present study. Therefore, the influence of tensile stress on crack arrest could be studied in the future to enrich and perfect the rock blasting theory.

\section{Acknowledgements}

The authors are grateful for the support provided by the National Natural Science Foundation of China (Grant No: 51974316).

This is an Open Access article distributed under the terms of the Creative Commons Attribution License

\section{References}

1. Faramarzi, F., Mansouri, H., Farsangi, M. A. E., "Development of rock engineering systems-based models for flyrock risk analysis and prediction of flyrock distance in surface blasting". Rock Mechanics and Rock Engineering, 47(4), 2014, pp.1291-1306.
2. Konicek, P., Soucek, K., Stas, L., Singh, R., "Long-hole destress blasting for rock burst control during deep underground coal mining". International Journal of Rock Mechanics and Mining Sciences, 61(5), 2013, pp.141-153. 
Liyun Yang, Chen Huang, Chenxi Ding, Huanzhen Xie and Yuh J. Chao/

\section{Journal of Engineering Science and Technology Review 13 (1) (2020) 193 - 203}

3. Yang, R. S., Ding, C. X., Yang, L. Y., Lei, Z., Zhang, Z., Wang, Y. B., "Visualizing the blast-induced stress wave and blasting gas action effects using digital image correlation". International Journal of Rock Mechanics and Mining Sciences, 112, 2018, pp. 47-54.

4. Dick, R. A., Fletcher, L. R., D'Andrea, D. V., "Explosives and blasting procedures manual" 1983, US Department of the Interior, Bureau of Mines.

5. Marko, B., Celso, R., Deane, R., "Finite element analysis of blastinduced fracture propagation in hard rocks". Computers and Structures, 182, 2017, pp.1-13.

6. Cho, S. H., Kaneko, K., "Influence of the applied pressure waveform on the dynamic fracture processes in rock". International Journal of Rock Mechanics and Mining Sciences, 41(5), 2004, pp.771-784.

7. Yue, Z. W., Zhang, S. C., Qiu, P., Li, Z., Yuan, K., "Influence of charge structures on the slotted cartridge blasting effect". Journal of Vibration and Shock, 37(10), 2018, pp.27-34.

8. Yue, Z. W., Tian, S. Y., Zhang, S. C., Zong, L. L., Xu, S. N., "Expanding law of cracks formed by slotted cartridge blast under unidirectional confining pressure". Journal of Vibration and Shock, 38(23), 2019, pp.186-195.

9. Wang, Z. L., Konietzky, H., "Modelling of blast-induced fractures in jointed rock masses". Engineering Fracture Mechanics, 76(12), 2009, pp.1945-1955.

10. Yang, L. Y., Ma, J. H., Wang, X. D., Zhang, W. C., Zhang, L., "Experimental study on blasting crack initiation and propagation behavior in compression stress field". Explosion and Shock Waves, 37(2), 2017, pp.262-268.

11. Yang, R. S., Ding, C. X., Li, Y. L., Yang, L. Y., Zhao, Y., “Crack propagation behavior in slit charge blasting under high static stress conditions". International Journal of Rock Mechanics and Mining Sciences, 119, 2019, pp.117-123.

12. Yilmaz, O., Unlu, T., "Three dimensional numerical rock damage analysis under blasting load". Tunnelling Underground Space Technology, 38, 2013, pp.266-278.

13. Kwon, S., Lee, C. S., Cho, S. J., Jeon, S. W., Cho, W. J., “An investigation of the excavation damaged zone at the KAERI underground research tunnel". Tunnelling and Underground Space Technology, 24(1), 2009, pp.1-13.

14. Lu, W., Chen, M., Geng, X., Shu, D., Zhou, C., "A study of excavation sequence and contour blasting method for underground powerhouses of hydropower stations". Tunnelling and Underground Space Technology, 29(29), 2012, pp.31-39.
15. Xie, L. X., Lu, W. B., Zhang, Q. B., Jiang, Q. H., Wang, G. H., Zhao, J. "Damage evolution mechanisms of rock in deep tunnels induced by cut blasting". Tunnelling and Underground Space Technology, 58, 2016, pp.257-270.

16. Soh, A. K., Yang, C. H., "Numerical modeling of interactions between a macro-crack and a cluster of micro-defects". Engineering Fracture Mechanics, 71(2), 2004, pp.193-217.

17. Haeri, H., Shahriar, K., Marji, M. F., Moarefvand, P., "Experimental and numerical study of crack propagation and coalescence in pre-cracked rock-like disks". International Journal of Rock Mechanics and Mining Sciences, 2014, 67:20-28.

18. Bhandari, S., Badal, R., "Post-blast studies of jointed rocks". Engineering Fracture Mechanics, 35(1), 1990, pp.439-445.

19. Babanouri, N., Mansouri, H., Nasab, S. K., Bahaadini, M. "A coupled method to study blast wave propagation in fractured rock masses and estimate unknown properties". Computers and Geotechnics, 49(49), 2013, pp.134-142.

20. Li, M., Zhu, Z., Liu, R., Liu, B., Zhou, L., Dong, Y. "Study of the effect of empty holes on propagating cracks under blasting loads". International Journal of Rock Mechanics and Mining Sciences, 103, 2018, pp.186-194.

21. Aliabadian, Z., Sharafisafa, M., Mortazavi, A., Maarefvand, P., "Wave and fracture propagation in continuum and faulted rock masses: distinct element modeling". Arabian Journal of Geosciences, 7(12), 2014, pp.5021-5035.

22. Yang, L. Y., Ding, C. X., "Fracture mechanism due to blastimposed loading under high static stress conditions". International Journal of Rock Mechanics and Mining Sciences, 107, 2018, pp.150-158.

23. Yang, R., Ding, C., Yang, L. Y., Chen, C., "Model experiment on dynamic behavior of jointed rock mass under blasting at high-stress conditions". Tunnelling and Underground Space Technology, 74, 2018, pp.145-152.

24. Kutter, H. K., Fairhurst, C., "On the fracture process in blasting". International Journal of Rock Mechanics and Mining Sciences \& Geomechanics Abstracts. 8(3), 1971, pp.181-202.

25. Rossmanith, H. P., Fourney, W. L., "Fracture initiation and stress wave diffraction at cracked interfaces in layered media I. brittle/brittle transition". Rock Mechanics, 14, 1982, pp.209-233.

26. Yang, R. S., Ding, C. X., Yang, L. Y., Xu, P., Chen, C., "Hole defects affect the dynamic fracture behavior of nearby running cracks". Shock and Vibration, 5894356, 2018, pp.1-8.

27. Establishment, C. A., "Stress intensity factor handbook". Beijing: Science and Technology Press, China, 1981. 